\title{
CLINICAL EVALUATION OF POTENTIAL ANTI-INFLAMMATORY EFFECT OF VITAMIN D3 ADJUVANT THERAPY FOR CHRONIC ASTHMA IN IRAQI PATIENTS
}

\author{
RASHA SAADI ABBAS ${ }^{1}$, MANAL KHALID ABDULRIDHA ${ }^{1 *}$, MOSTAFA ABDALFATAH SHAFEK ${ }^{2}$ \\ 1Department of Clinical Pharmacy, College of Pharmacy, Al-Mustansiriyah University, Baghdad, Iraq, ${ }^{2}$ Department of Internal Medicine; \\ Al-Yarmouk Teaching Hospital; Baghdad, Iraq \\ Email: pharm.mrdha@uomustansiriyah.edu.iq \\ Received: 01 Oct 2016 Revised and Accepted: 11 Nov 2016
}

\begin{abstract}
Objective: This study was designed to evaluate the potential anti-inflammatory effect of vitamin $\mathrm{D}_{3}$ supplementation in Iraqi patients with chronic asthma.

Methods: Forty-four candidate patients were diagnosed with asthma during their visit to hospital allocated as 20 patients assigned to receive conventional therapy for asthma and 24 patients assigned to receive conventional therapy for asthma plus $2000 \mathrm{I}$. U vitamin $\mathrm{D}_{3}$ tablet for three months period. Also, 30 apparently healthy subjects were included in the study as a control group. Pulmonary function test, serum 25-OH vitamin D levels, serum Interlukin-10 (IL-10) levels, serum tumor necrosis factor alpha (TNF- $\alpha$ ) levels were measured before and after three months therapy.

Results: After three months treatment, there was a highly significant improvement in both measured and percentage of predicted value of pulmonary function test (PFT) compared to the pre-treatment value for both group 1 and group 2 patients ( $p<0.01$ ). Also, a highly significant increase in total endogenous vitamin D level in group 2 when compared to group 1 patients after three months period ( $p<0.01)$. Group 2 patients presented with a significant increase in mean IL-10 after three months of treatment when compared to pre-treatment level $(p<0.05)$. The mean TNF- $\alpha$ level was increased non-significantly in both study groups, but the higher level was found in group 1 patients than in group 2 patients when compared to pre-treatment level $(p>0.05)$
\end{abstract}

Conclusion: There was a significant increase in the level of anti-inflammatory biomarker interleukin-10 (IL-10), though no clear effect on tumor necrosis factor- $\alpha$ (TNF- $\alpha$ ) was noticed after three months treatment with vitamin $\mathrm{D}_{3}$ supplementation.

Keywords: Asthma, Endogenous vitamin $\mathrm{D}_{3}$, Pulmonary function test, Anti-Inflammatory markers

(C) 2017 The Authors. Published by Innovare Academic Sciences Pvt Ltd. This is an open access article under the CC BY license (http://creativecommons.org/licenses/by/4. 0/] DOI: http://dx.doi.org/10.22159/ijpps.2017v9i1.15487

\section{INTRODUCTION}

Asthma is a chronic inflammatory disorder of the airways in which many cells and cellular elements play a role especially, mast cells, neutrophils, eosinophils, T lymphocytes, macrophages, and epithelial cells [1]. Asthma is usually associated with chronic inflammation of the mucosa from the trachea to terminal bronchioles but with a predominance in the bronchi (cartilaginous airways) [2]. Macrophage has the capacity to initiate inflammatory response via the release of a certain type of cytokines but can also release anti-inflammatory mediators, such as interleukin-10 (IL-10), which its secretion is reduced in alveolar macrophages of asthmatic patients [3].

Dendritic cells are specialised cells that have a unique ability to induce a T-lymphocyte mediated immune response and therefore play a critical role in the development of asthma [4]. Immature dendritic cells promote $\mathrm{T}$ helper 2 (TH2) cell differentiation and require cytokines, such as interleukin-12 (IL-12) and tumour necrosis factor $\alpha$ (TNF- $\alpha$ ), to promote the normally predominant T helper-1 (TH1) response in the respiratory tract [4]. Vitamin D is an essential nutrient that is usually obtained through exposure to sunlight, and secondarily through diet and dietary supplements [5]. Vitamin D receptors (VDR) containing cells are targets for vitamin D activity [6], one of the superfamily of nuclear receptors [7], which is a critical molecule in calcium metabolism, bone turnover, and other immune and inflammatory disorders [8].

Vitamin D receptor in the lung have been proven to be fully functional when $25(\mathrm{OH}) \mathrm{D}$ is converted into active form $1,25(\mathrm{OH})_{2} \mathrm{D}$ in respiratory epithelial cells where increased synthesis of both VDR and CYP24A1 (a hydroxylase that metabolizes 1,25(OH)D) in bronchial smooth muscle cells has been recognized [9]. It is now well known that in the human body CYP27B1 and VDR are presented in cells involved in the immune/inflammation system which provides the biological mechanism of vitamin $\mathrm{D}$ in inflammatory diseases [10].

In macrophages, the active form of vitamin $\mathrm{D}\left(1,25(\mathrm{OH})_{2} \mathrm{D}_{3}\right)$ cause a reduction of gene expression and protein release of proinflammatory mediators, such as tumor necrosis factor-alpha (TNF$\alpha)$, interleukin-6 (IL-6), and monocyte chemo attractant protein-1 (MCP-1), result in reduction of monocytes/macrophages recruitment and overall inflammation within tissue [11-13].

Vitamin D deficiency lower steroid-induced production of IL-10 and decreasing the anti-inflammatory activity of glucocorticoids while vitamin D supplementation reverses steroid resistance [14]. Nevertheless, vitamin D oral supplementation for $7 \mathrm{~d}$ in steroidrefractory patients with asthma restored the dexamethasone induction of IL-10 [15].

Accordingly, this study was designed to evaluate the potential antiinflammatory effect of vitamin $\mathrm{D}_{3}$ supplementation on the level of pro-inflammatory mediator tumor necrosis factor- $\alpha$ (TNF- $\alpha$ ) and anti-inflammatory cytokine interleukin-10 (IL-10) in Iraqi patients with chronic asthma.

\section{MATERIALS AND METHODS}

Study design

This is a prospective randomised controlled open-label interventional study to evaluate the anti-inflammatory effect of vitamin $\mathrm{D}_{3}$ in asthma patients.

\section{Patients}

Forty-four candidate patients were diagnosed with asthma during their visit to the hospital. The patients were under the supervision of 
a pulmonary specialist and were treated according to clinical practice guideline and disease severity.

The local clinical research ethics committee, in accordance with Helsinki declaration 1998, approved the study protocol and all subjects gave written informed consent to participate in the study. The eligible patients and subjects were allocated into three main groups:

Group 1: Include 20 patients who have diagnosed with asthma are assigned to receive conventional therapy for asthma according to disease stage and severity for three months period.

Group 2: Include 24 patients who have diagnosed with asthma are assigned to receive conventional therapy for asthma according to disease stage and severity plus $2000 \mathrm{I}$. U vitamin $\mathrm{D}_{3}$ fast dissolve mini tablet (Natrol, USA) for three months period.

Control group: Include 30 apparently healthy control subjects.

\section{Material and methods}

\section{- Pulmonary function test (PFT) using spirometry}

It was measured using Spiro Air (volumetric P. F. T), (Medisoft, Belgium) in which forced vital capacity (FVC), forced expiratory volume in one second (FEV1), peak expiratory flow (PEF) both the measured and percentage of predicted value in addition to forced expiratory volume in one second/forced vital capacity (FEV1/FVC) ratio were measured before and after three months therapy for both group 1 and group 2 patients.

\section{- Specimens collection}

Five millilitre of venous blood were drawn using a plastic disposable syringe and collected in the plain disposable tube (gel and clot activator) and was allowed to clot and separated by centrifuge at a speed of $3000 \mathrm{rpm}$ for $10 \mathrm{~min}$. The serum samples were stored at ($40^{\circ} \mathrm{C}$ ) until the time of examination.

\section{- Serum 25-0H vitamin D level measurement}

It was determined using commercial enzyme-linked immunesorbent assay (ELISA) kit (Euroimmun, Germany), measured at baseline in group 1, group 2 patients and healthy control groups and after three months treatment in group 1 and group 2 patients.

- Serum Interleukin-10 (IL-10), Tumor necrosis factor- $\alpha$ (TNFa) level measurement

It was determined using commercial enzyme-linked immunosorbent assay (ELISA) kit (Elabscience Biotechnology, China) measured before and after three months therapy for both groups 1 and group 2 patients.

\section{- Body mass index (BMI) measurement}

Body Mass Index (BMI) is an individual weight in kilogrammes divided by the square of their height in meters $(\mathrm{kg} / \mathrm{m} 2)$.

\section{Statistical analysis}

The Statistical Analysis System Minitab 16.1 (2010) were used. Data presented as (mean \pm SD). Pearson Chi-square test was utilized to detect significant differences among demographic variables, while paired $t$-test was used to compare between pre-and post-treatment results, two sample $t$-test used to compare pre or post treatment between group 1 and 2. Analysis of Variance (ANOVA) was utilized to compare between the studied parameters among different patient groups.

NS: no significant differences $(p>0.05),(*)$ significant difference $\left.(p<0.05),{ }^{* *}\right)$ highly Significant difference $(p<0.01)$.

\section{RESULTS}

\section{Patients demographic and disease characteristics}

Table 1 demonstrates the patient demographic and disease characteristic for 74 subjects including 53 female (71.6\%) and 21 male genders $(28.4 \%)$ with no significant statistical difference was found among study groups in respect to both genders ( $p>0.05)$.

The age range for the groups where between 14-71 y with the mean age of the study groups were as follows: group1 patients $(40.75 \pm 17.31)$ years, and group 2 patients $(41.4 \pm 13.6)$ years, control group (45.86 \pm 15.83$)$ years with no significant statistical difference was found among study groups in respect to age $(p>0.05)$.

Positive family history of asthma was found in (65\%) and $(58.3 \%)$ of group 1 and group 2 patients respectively while negative family history was found in (35\%) and (41.7\%) for group 1 and group 2 patients respectively with no significant statistical difference between these groups $(p>0.05)$. Considering the patient's residence there were $(85 \%)$ of group1 patients versus $(79.2 \%)$ of group 2 patients were urban, and $(15 \%)$ of group 1 patients versus $(20.8 \%)$ of group 2 patients were rural with no significant statistical difference between both groups $(p>0.05)$.

The duration of the disease for group 1 and group 2 patients respectively were as follows: $(80 \%)$ versus $(62.5 \%)$ for less than $20 \mathrm{y}$, $(15 \%)$ versus $(25 \%)$ for $(21-40)$ years duration, $(5 \%)$ versus $(12.5 \%)$ for (41-60) years duration, with a mean of $(12.8 \pm 11.2)$ years for group 1 patients and $(20.2 \pm 15.4)$ years for group 2 patients respectively and no significant statistical difference was found between both groups in respect to duration of the disease $(p>0.05)$.

The mean body mass index (BMI) for group 1 patients was $(33.20 \pm 8.54) \mathrm{kg} / \mathrm{m}^{2}$ and $(29.25 \pm 7.44) \mathrm{kg} / \mathrm{m}^{2}$ for group 2 patients with no significant statistical difference was found between study groups in respect to the BMI $(p>0.05)$.

Table 1: Patients demographic and disease characteristics

\begin{tabular}{|c|c|c|c|c|}
\hline \multirow[t]{2}{*}{ Variable } & \multicolumn{4}{|l|}{ Study groups } \\
\hline & Group 1 & Group 2 & Control group & $P$ value \\
\hline Age (year) & $40.75 \pm 17.31^{\mathrm{aNS}}$ & $41.4 \pm 13.6^{\mathrm{aNS}}$ & $45.86 \pm 15.83$ & $0.890^{\mathrm{bNS}}$ \\
\hline BMI $\left(\mathrm{kg} / \mathrm{m}^{2}\right)$ & $33.20 \pm 8.54$ & $29.25 \pm 7.44$ & ------ & $0.114^{\mathrm{NS}}$ \\
\hline Gender & $\mathrm{n}(\%)$ & $\mathrm{n}(\%)$ & $\mathrm{n}(\%)$ & \\
\hline Female & $13(65.0)$ & $20(83.3)$ & $20(66.7)$ & $0.299^{\mathrm{NS}}$ \\
\hline Male & $7(35.0)$ & $4(16.7)$ & $10(33.3)$ & \\
\hline Total & $20(100)$ & $24(100)$ & $30(100)$ & \\
\hline Family history & $\mathrm{n}(\%)$ & $\mathrm{n}(\%)$ & $\mathrm{n}(\%)$ & $0.651^{\mathrm{NS}}$ \\
\hline Positive & $13(65.0)$ & $14(58.3)$ & ------ & \\
\hline Negative & $7(35.0)$ & $10(41.7)$ & ------ & \\
\hline Residence & $\mathrm{n}(\%)$ & $\mathrm{n}(\%)$ & $\mathrm{n}(\%)$ & $0.617^{\mathrm{NS}}$ \\
\hline Urban & $17(85.0)$ & 19(79.2) & ------ & \\
\hline Rural & $3(15.0)$ & $5(20.8)$ & ------ & \\
\hline Duration of the disease (year) & $\mathrm{n}(\%)$ & $\mathrm{n}(\%)$ & $\mathrm{n}(\%)$ & $0.072^{\mathrm{NS}}$ \\
\hline$\leq 20$ & $16(80.0)$ & $15(62.5)$ & -..-- & \\
\hline $21-40$ & $3(15.0)$ & $6(25.0)$ & ------ & \\
\hline $41-60$ & $1(5.0)$ & $3(12.5)$ & ------ & \\
\hline$\geq 61$ & None & None & ------ & \\
\hline
\end{tabular}

Data presented as mean $\pm \mathrm{SD}$, a number of patients (n) and percentage (\%), a: comparison with control group, b: comparison between group 1 and 2 , NS: no significant differences $(p>0.05)$. 
Effect of conventional therapy alone and in combination with vitamin $D_{3}$ supplement on pulmonary function test (PFT), (spirometry) in asthmatic patients

The mean forced vital capacity (FVC), mean forced expiratory volume in one second (FEV1), and mean peak expiratory flow (PEF) both the measured and the percentage of predicted value showed no significant difference at baseline and after three months between the study groups $(1,2)(p>0.05)$ while highly significant increase was noticed after three months treatment compared to pre-treatment value for both group 1 and group 2 patients $(p<0.01)$.

The mean forced expiratory volume in one second/forced vital capacity (FEV1/FVC) ratio showed a significant difference at baseline level between group 1 and group $2(p<0.05)$, but no significant differences was found after three months between both groups $(p>0.05)$. There was no significant increase in (FEV1/FVC) ratio after three months in group 1 when compared to pre- treatment value ( $p>0.05)$, nevertheless, group 2 showed a highly significant increase after three months treatment compared to pretreatment value $(p<0.01)$ as shown in table 2 .

Effect of conventional therapy alone and in combination with vitamin $D_{3}$ supplement on total endogenous vitamin $D$ level in asthmatic patients

Table 3 showed that at the baseline (pre-treatment) mean level of endogenous vitamin D showed no significant differences when comparing group 1 with control and group $2(p>0.05)$, meanwhile a highly significant difference was between group 2 and control group $(p<0.01)$. Following treatment for three months, there was highly significant increase in endogenous vitamin D level in group 2 when compared to group 1 patients $(p<0.01)$. A highly significant increase in endogenous vitamin D level post-treatment was found in both study groups 1 and 2 compared to pretreatment level $(p<0.01)$.

Table 2: Effect of conventional therapy alone and in combination with vitamin $D_{3}$ supplement on pulmonary function test (PFT) (spirometry) in asthmatic patients treated for three months

\begin{tabular}{|c|c|c|c|}
\hline Variable & Study groups & & \\
\hline FVC(L) Meas. & Group1 & Group 2 & $P$ value \\
\hline Pre-treatment & $2.113 \pm 1.075$ & $1.840 \pm 0.583$ & $0.317^{\mathrm{NS}}$ \\
\hline Post-treatment & $2.655 \pm 1.107$ & $2.415 \pm 0.733$ & $0.414^{\mathrm{NS}}$ \\
\hline$P$-value & $0.000^{* *}$ & $0.000^{* *}$ & ------ \\
\hline FVC(\%Pred. Val.) & Group1 & Group 2 & $P$ value \\
\hline Pre-treatment & $58.60 \pm 17.97$ & $57.33 \pm 17.71$ & $0.816^{\mathrm{NS}}$ \\
\hline Post-treatment & $75.15 \pm 12.52$ & $74.04 \pm 18.55$ & $0.815^{\mathrm{NS}}$ \\
\hline$P$-value & $0.000^{* *}$ & $0.000^{* *}$ & ------ \\
\hline FEV1(L) Meas. & Group1 & Group 2 & $P$ value \\
\hline Pre-treatment & $1.584 \pm 0.871$ & $1.189 \pm 0.514$ & $0.084^{\mathrm{NS}}$ \\
\hline Post-treatment & $2.091 \pm 1.013$ & $1.753 \pm 0.674$ & $0.212^{\mathrm{NS}}$ \\
\hline$P$-value & $0.009^{* *}$ & $0.000 * *$ & ------ \\
\hline FEV1(\%Pred. Val.) & Group1 & Group 2 & $P$ value \\
\hline Pre-treatment & $50.90 \pm 16.04$ & $43.92 \pm 20.36$ & $0.210^{\mathrm{NS}}$ \\
\hline Post-treatment & $68.85 \pm 14.93$ & $63.04 \pm 20.68$ & $0.287^{\mathrm{NS}}$ \\
\hline$P$-value & $0.003^{* *}$ & $0.000^{* *}$ & ------ \\
\hline FEV1/FVC(\%) & Group1 & Group 2 & $P$ value \\
\hline Pre-treatment & $74.37 \pm 13.25$ & $63.62 \pm 14.33$ & $0.013^{*}$ \\
\hline Post-treatment & $78.30 \pm 12.58$ & $71.45 \pm 13.15$ & $0.086^{\mathrm{NS}}$ \\
\hline$P$-value & $0.341^{\mathrm{NS}}$ & $0.005^{* *}$ & ------ \\
\hline PEF(L/S) Meas. & Group1 & Group 2 & $P$ value \\
\hline Pre-treatment & $3.209 \pm 1.361$ & $2.383 \pm 1.155$ & $0.039 *$ \\
\hline Post-treatment & $4.158 \pm 1.557$ & $3.422 \pm 1.496$ & $0.120^{\mathrm{NS}}$ \\
\hline$P$-value & $0.007^{* *}$ & $0.001^{* *}$ & ------ \\
\hline PEF (\%Pred. Val.) & Group1 & Group 2 & $P$ value \\
\hline Pre-treatment & $44.65 \pm 14.41$ & $36.21 \pm 17.81$ & $0.090^{\mathrm{NS}}$ \\
\hline Post-treatment & $58.30 \pm 16.01$ & $50.92 \pm 19.54$ & $0.176^{\mathrm{NS}}$ \\
\hline$P$-value & $0.001^{* *}$ & $0.000^{* *}$ & ------- \\
\hline
\end{tabular}

Data presented as mean \pm SD, FVC(L): forced vital capacity in liter,FEV1(L): forced expiratory volume in one second in liter, FEV1/FVC: forced expiratory volume in one second/forced vital capacity ratio, $\operatorname{PEF}(\mathrm{L} / \mathrm{S})$ : peak expiratory flow in liter per second, \% Pred. Val.: percentage of predicted value, Meas.: measured value, NS: no significant differences $(p>0.05),\left({ }^{*}\right)$ significant difference $(p<0.05),(* *)$ highly significant difference $(p<0.01)$.

Table 3: Effect of conventional therapy alone and in combination with vitamin $D_{3}$ supplement on total endogenous vitamin $D$ level in asthmatic patients treated for three months

\begin{tabular}{|c|c|c|c|c|}
\hline Variable & Study groups & & & \\
\hline Endogenous Vitamin D (ng/ml) & Group 1 & Group 2 & Control group & $P$ value \\
\hline Pre-treatment & $8.90 \pm 6.82^{\mathrm{aNS}}$ & $6.33 \pm 4.64^{\mathrm{a}^{* *}}$ & $13.26 \pm 9.06$ & $0.162^{\mathrm{bNS}}$ \\
\hline Post-treatment & $12.59 \pm 7.08$ & $23.25 \pm 8.73$ & ------ & $0.000^{* *}$ \\
\hline$P$-value & $0.002^{* *}$ & $0.000^{* *}$ & ------ & ------ \\
\hline
\end{tabular}

Data presented as mean \pm SD, Endogenous vitamin D measured as (25-OH vitamin D), a: comparison with control group, b: comparison between group 1 and group 2, NS: no significant differences $(p>0.05),(* *)$ highly significant difference $(p<0.01)$.

Effect of conventional therapy alone and in combination with vitamin $D_{3}$ supplement on interleukin-10 (IL-10) and tumor necrosis factor alpha (TNF- $\alpha$ ) level in asthmatic patients

Table 4 showed no significant difference of mean interleukin-10 (IL10) level at the baseline and post-treatment between both study groups (1and 2) ( $p>0.05)$. After three months of treatment, group 1 patients had no significant increase in the mean IL-10 compared to pre-treatment level $(p>0.05)$, while in group 2 patients there was a significant increase in mean IL-10 after three-month treatment compared to pre-treatment level $(p<0.05)$. 
On the other hand, at the baseline, there was a significant difference in mean level of tumor necrosis factor alpha (TNF- $\alpha$ ) between group 1 and group 2 patients $(p<0.05)$ but no significant differences was seen post-treatment between both study groups $(p>0.05)$. After three months of treatment, the mean TNF- $\alpha$ level was increased non-significantly in both study groups, but the higher level was found in group 1 patients than in group 2 patients when compared to pre-treatment level ( $p>0.05)$.

Table 4: Effect of conventional therapy alone and in combination with vitamin $D_{3}$ supplement on interleukin-10 (IL-10) and tumor necrosis factor alpha (TNF- $\alpha$ ) level in asthmatic patients treated for three months

\begin{tabular}{llll}
\hline Variable & Study groups & \\
\hline IL-10 $(\mathrm{pg} / \mathrm{ml})$ & Group 1 & Group 2 & \\
Pre-treatment & $29.5 \pm 5.17$ & $37.0 \pm 8.64$ & \\
Post-treatment & $43.4 \pm 11.49$ & $73.1 \pm 16.89$ & $0.460^{\text {NS }}$ \\
$P$-value & $0.281^{\text {NS }}$ & $0.029^{*}$ & $0.156^{\text {NS }}$ \\
TNF- $\alpha(\mathrm{pg} / \mathrm{ml})$ & Group 1 & Group 2 & \\
Pre-treatment & $23.5 \pm 5.74$ & $44.9 \pm 7.82$ & $P$ value \\
Post-treatment & $48.9 \pm 22.14$ & $48.4 \pm 11.88$ & $0.033^{*}$ \\
$P$-value & $0.202^{\text {NS }}$ & $0.750^{\text {NS }}$ & $0.985^{\text {NS }}$ \\
\hline
\end{tabular}

Data presented as mean \pm SD, NS: no significant differences $(p>0.05),\left({ }^{*}\right)$ significant difference $(p<0.05),\left({ }^{* *}\right)$ highly significant difference $(p<0.01)$.

\section{DISCUSSION}

Approximately $5-15 \%$ of patients with asthma symptoms and exacerbation are uncontrolled despite of routine controller medications including corticosteroids [16]. Part of this variability may be explained by endogenous vitamin D levels; some studies suggested that vitamin D may enhance the effects of inhaled corticosteroids [16-18]. Vitamin D might protect against inflammatory reactions to environmental pollutants and might be broadly important in regulating chronic inflammation of the lung [19]. Nutrition has represented an important conditioning factor of many chronic diseases with many studies explore the role of adjuvant therapy in the treatment of asthma-like antioxidant vitamins, trace elements [20], and essential oils like gamma linoleic acid $[21,22]$. Up to the best knowledge, there is no clinical study reported for Iraqi adult population to explore the role of vitamin $\mathrm{D}_{3}$ supplement in asthma. Thus, the present study was undertaken to clinically evaluate whether or not vitamin $\mathrm{D}_{3}$ can improve pulmonary function and health-related quality of life in asthmatic patients concomitantly with reduction of inflammatory and oxidative burden in those patients.

In the present study, both genders were enrolled in the study with a slight predominance of female over the male in both study groups (3:1). This was consistent with another previous study since adult females are more severely affected by asthma and raise the possibility that hormonal or biochemical differences related to sex might play a role in the pathophysiology of asthma [23].

Positive family history to asthma was found in more than (50\%) in both groups of the present study. Al-Kubaisy et al. in 2004 studied the effect of family history among asthmatic primary school children and noticed that child of asthmatic father, mother or sibling were higher rate and considered a significant risk factor for having asthma by their index child [24]. These results were supported by another study were asthma are highest among those who had more than one first-degree relative with asthma and identify sex-specific differences in the risk of asthma in relation to heredity factor [25]

Most of the asthmatic patients enrolled in this study were resident in urban rather than rural area, and were more prone to be exposed to ambient air pollution [26]. High levels of vehicle emissions, westernised lifestyle, with increasing indoor allergens exposure such as house dust mite and animal dander all may explain differences in asthma prevalence and morbidity among adults in urban versus rural areas [24,27]

Epidemiological studies worldwide allowed such explanations, in Rwanda, Musafiri et al. investigated the prevalence of atopy and asthma between urban and rural area, higher prevalence of asthma was found in the urban area [28]. Inversely, in New Zealand, the rate of asthma hospitalisation was higher in rural areas than in urban areas [29]. The possible explanation for the diversity is the fact that most people have different lifestyles and cultures, in addition to different environmental and genetic backgrounds [27].

With reference to the results in the present study, highly significant increase in both measured and percentage of predicted value in forced vital capacity (FVC), forced expiratory volume in one second (FEV1), and peak expiratory flow (PEF) in both study groups after three months treatment when compared to pre-treatment value suggesting that this improvement was due to conventional therapy rather the effect of vitamin $\mathrm{D}_{3}$ supplementation. On the other hand highly significant increase in the ratio of forced expiratory volume in one second/forced vital capacity (FEV1/FVC) in group 2 after three months treatment with vitamin $\mathrm{D}_{3}$ supplementation when compared to group 1, $(p<0.01)$. Columbo et al. (2014) found no significant association between serum vitamin $\mathrm{D}$ and spirometric values, and vitamin D was similar in subjects with lower FEV1\% (<70\%), also no variation in the spirometric values had been obtained after a $12 \mathrm{w}$ treatment with 2000 IU vitamin D3 supplementation [30].

Additionally, Nageswari et al. (2014) investigated the addition of 1000 IU of vitamin $\mathrm{D}_{3}$ to conventional therapy when compared to conventional therapy alone on pulmonary function test, he found that patients in both groups had a significant improvement in the percentage of predicted value of (FEV1) after three months treatment [31]

In the present study, asthmatic patients showed a significant decline in mean total endogenous vitamin D level compared to healthy controls. Following vitamin D supplementation, post treatment, highly significant increase in the mean of the total endogenous vitamin D level in both asthmatic groups when compared to pretreatment level. These finding can be explained by the following point, first; in the present study, serum 25-OH vitamin D level was measured which is considered the best circulating biomarker of vitamin D metabolic status since it reflects total vitamin D from dietary intake and sunlight exposure as well as the conversion of vitamin D from adipose tissue in the liver [32], accordingly we can't estimate the active vitamin D acquired from sunlight exposure or diet. Second, a higher significant increase in the mean of endogenous vitamin D level in group 2 when compared to group 1 post treatment with vitamin $\mathrm{D}_{3}$ supplement to conventional therapy provided a good estimation of the potential effect of vitamin D in asthma control. These findings are in agreement with Menon et al. who reported that highly significant elevation of mean vitamin D level in both control group (asthmatic patients received standard medication only) and study group (asthmatic patients received standard therapy along with oral vitamin D (1000 IU) for $8 \mathrm{w}$ ) [33]. The lowest value of serum vitamin $D$ was found in severely exacerbated asthma patients in which vitamin D promotes steroid sensitivity in the body and can downregulate an inflammatory state via gene expression and cytokine production, consequently vitamin D deficiency could be associated with an inability to switch off the inflammatory state [34]. 
This study was interested in tracking the changes in inflammatory cascade following adjuvant vitamin D therapy in asthmatic patients. A significant increase of mean interleukin-10 (IL-10) level in group 2 patients was found after three months, meanwhile, group 1 showed no significant increase of this anti-inflammatory cytokine suggesting a potential role of vitamin D on its activation. Aldubi et al.(2015) found that Serum 25-hydroxyvitamin D levels were positively correlated to the anti-inflammatory cytokine IL-10 and linked between reduced IL-10 levels and lung function in children with severe asthma, partly be explained by hypovitaminosis [35]. Another finding showed a positive correlation between serum 25hydroxyvitamin D level and Broncho alveolar lavage level of the anti-inflammatory cytokine interleukin (IL)-10 in severe resistant asthma in children [36]. Controversially, at the baseline Korn et al. found no link between serum vitamin D status and serum IL-10 concentrations (as IL-10 levels in patients with more severe and uncontrolled asthma did not differ from that in patients with mild/moderate or controlled/partly controlled asthma [37]. A finding previously noted by another researcher who found that the administration of vitamin $\mathrm{D}_{3}$ to healthy individuals and steroid resistant asthmatic patients enhanced subsequent responsiveness to dexamethasone for induction of IL-10 suggested that vitamin $\mathrm{D}_{3}$ could potentially increase the therapeutic response to glucocorticoids in steroid resistant patients [15].

Tumor necrosis factor alpha (TNF- $\alpha$ ) is a critical pro-inflammatory cytokine that might play an important role in severe refractory disease [38]. Reduced vitamin D levels are associated with increased expression of TNF- $\alpha$, suggesting that enhanced expression of this pro-inflammatory cytokine is a potential pathway by which reduced vitamin D levels could exert pro-inflammatory effects in asthma [39]. The present study found that TNF- $\alpha$ increased in both study groups ( 1 and 2 ) after three months treatment, but not significant. When comparing mean differences in TNF- $\alpha$ level, it can be recognised that minimum increase in group 2 compared to the higher increase in group 1. Longer duration of vitamin $D_{3}$ supplementation might be required to explore the effect clearly. It was proposed that to achieve optimal anti-inflammatory effects by vitamin $\mathrm{D}$, it is important to maintain serum vitamin D levels of greater than $(30 \mathrm{ng} / \mathrm{ml})$ in the physiologic range $[40,41]$. Recent study showed that serum TNF- $\alpha$ in vitamin D deficiency patients with severe asthma exacerbation was significantly increased compared to that in vitamin D sufficient patients, suggested that vitamin $\mathrm{D}_{3}$ is a potential anti-inflammatory agent by attenuating the generation of TNF- $\alpha$, blocking reactive oxygen species generation, and nuclear factor (NFkB) activation pathways in lipopolysaccharides (LPS) stimulated airway epithelial cells [42]. All these observations suggested that evaluation of serum vitamin D concentrations should be considered in adult patients with asthma that responds suboptimally to ICS, and they give a promising preventive strategy that vitamin $\mathrm{D}_{3}$ supplementation could result in improvement of these phenotypic variables in the subset of subjects with asthma who are vitamin D deficient [43].

The present study has few limitation including small sample size with different disease severity which required to verify the findings, short duration of patient follow-up, as longer period may be required to explore good results. In addition to some missing data in respect to lifestyle details of asthmatic patients (vitamin D acquires through sunlight exposure or from diet) and inability to restore vitamin $\mathrm{D}$ to the normal level prior to the study in order to explore the actual effect of vitamin $\mathrm{D}_{3}$ supplementation on asthma parameter rather than replace of deficiency.

\section{CONCLUSION}

In the present study, many promising preventive strategies emerged from the available results since vitamin $D$ relatively improve pulmonary function in asthmatic patients concomitantly with reduction of inflammatory burden in those patients, suggesting that vitamin D plays effective role to be a good candidate as an adjuvant therapy. Further evaluation is needed to explore the potential effect of vitamin D supplementation in acute or chronic asthma after recovering hypovitaminosis and optimisation of endogenous vitamin D status.

\section{ACKNOWLEDGMENT}

The author would like to thank Al-Mustansiriyah University (www.uomustansiriyah.edu.iq) Baghdad - Iraq for its support in the present work and special thanks to Al-Yarmouk Teaching Hospital for their help in providing the practical platform of this study.

\section{CONFLICT OF INTERESTS}

Declared none

\section{REFERENCES}

1. Self $\mathrm{TH}$, Chrisman CR, Finch CK. Asthma. In: Alldredge BK, Corelli RL, Ernst ME, Guglielmo BJ, Jacobson PA, Kradjan WA, et al. Koda-kimble and Young's applied therapeutics: the clinical use of drugs. 10th ed. Philadelphia: Lippincott Williams and Wilkins; 2013. p. 565-600.

2. Barnes PJ. Asthma. In: Loscalzo J, Fauci AS, Kasper DL, Longo DL, Braunwald E, Hauser SL, et al. Harrison's pulmonary and critical care medicine. New York: McGraw-Hill; 2010. p. 60-78.

3. John M, Lim S, Seybold J, Jose P, Robichaud A, O'Connor B, et al. Inhaled corticosteroids increase IL-10 but reduce MIP-1a, GM$\mathrm{CSF}$ and IFN- $\gamma$ release from alveolar macrophages in asthma. Am J Respir Crit Care Med 1998;157:256-62.

4. Barnes PJ. Pathophysiology of asthma. ERS J 2003;23:84-113.

5. Lange NE, Litonjua A, Hawrylowicz CM, Weiss S. Vitamin D, the immune system and asthma. Expert Rev Clin Immunol 2009;5:693-702.

6. Iqbal SF, Freishtat RJ. Mechanism of action of vitamin D in the asthmatic lung. J Investig Med 2011;59:1200-2.

7. Nagy L, Szanto A, Szatmari I, Szeles L. Nuclear hormone receptors enable macrophages and dendritic cells to sense their lipid environment and shape their immune response. Physiol Rev 2012;92:739-89.

8. Pfeffer PE, Hawrylowicz CM. Vitamin D and lung disease. Thorax 2012;67:1018-20.

9. Hansdottir S, Monick MM, Hinde SL, Lovan N, Look DC, Hunninghake GW. Respiratory epithelial cells convert inactive vitamin D to its active form: potential effects on host defense. J Immunol 2008;181:7090-9.

10. Brennan A, Katz DR, Nunn JD, Barker S, Hewison M, Fraher LJ, et al. Dendritic cells from human tissues express receptors for the immunoregulatory vitamin D3 metabolite, dihydroxycholecalciferol. Immunology 1987;61:457-61.

11. Korf H, Wenes M, Stijlemans B, Takiishi T, Robert S, Miani M, et al. 1,25-Dihydroxyvitamin D3 curtails the inflammatory and $\mathrm{T}$ cell stimulatory capacity of macrophages through an IL-10dependent mechanism. Immunobiology 2012;217:1292-300.

12. Chen Y, Liu W, Sun T, Huang Y, Wang Y, Deb DK, et al. 1,25Dihydroxyvitamin $\mathrm{D}$ promotes negative feedback regulation of TLR signalling via targeting microRNA-155-SOCS1 in macrophages. J Immunol 2013;190:3687-95.

13. Zhang Y, Leung DY, Richers BN, Liu Y, Remigio LK, Riches DW, et al. Vitamin D inhibits monocyte/macrophage proinflammatory cytokine production by targeting MAPK phosphatase-1. J Immunol 2012;188:2127-35.

14. Berraies A, Hamzaoui K, Hamzaoui A. Link between vitamin D and airway remodeling. J Asthma Allergy 2014;7:23-30.

15. Xystrakis E, Kusumakar S, Boswell S, Peek E, Urry Z, Richards $\mathrm{DF}$, et al. Reversing the defective induction of IL-10-secreting regulatory $\mathrm{T}$ cells in glucocorticoid-resistant asthma patients. J Clin Invest 2006;116:146-55.

16. Clifford RL, Knox AJ. Vitamin D-A new treatment for airway remodelling in asthma? Br J Pharmacol 2009;158:1426-8.

17. Zhang Y, Leung DY, Goleva E. Anti-inflammatory and corticosteroid-enhancing actions of vitamin D in monocytes of patients with steroid-resistant and those with steroid-sensitive asthma. J Allergy Clin Immunol 2014;133:1744-52.

18. Searing DA, Zhang Y, Murphy JR, Hauk PJ, Goleva E, Leung DY. Decreased serum vitamin D levels in children with asthma are associated with increased corticosteroid use. J Allergy Clin Immunol 2010;125:995-1000.

19. Sandhu MS, Casale TB. The role of vitamin D in asthma. Ann Allergy Asthma Immunol 2010;105:191-9. 
20. Riccioni G, D'Orazio N. The role of selenium, zinc and antioxidant vitamin supplementation in the treatment of bronchial asthma: adjuvant therapy or not? Expert Opin Investig Drugs 2005;14:1145-55.

21. Hederos CA, Berg A. Epogam evening primrose oil treatment in atopic dermatitis and asthma. Arch Dis Child 1996;75:494-7.

22. Hussain MS, Abdulridha MK, Khudhair MS. Anti-inflammatory, antioxidant, and vasodilating effect of evening primrose oil in type 2 diabetic patients. Int J Pharm Sci Rev Res 2016;39:173-8.

23. Skobeloff EM, Spivey WH, St Clair SS, Schoffstall JM. The influence of age and sex on asthma admissions. JAMA 1992;268:3437-40.

24. Al-Kubaisy W, Ali SH, Al-Thamiri D. Risk factors for asthma among primary school children in Baghdad, Iraq. Saudi Med J 2005;26:460-6.

25. Paaso EM, Jaakkola MS, Lajunen TK, Hugg TT, Jaakkola JJ. The importance of family history in asthma during the first $27 \mathrm{y}$ of life. Am J Respir Crit Care Med 2013;188:624-6.

26. Von ME. The environmental predictors of allergic disease. J Allergy Clin Immunol 2000;105:9-19.

27. Jie Y, Isa ZM, Jie X, Ju ZL, Ismail NH. Urban vs. rural factors that affect adult asthma. Rev Environ Contam Toxicol 2013;226:33-63.

28. Musafiri S, van Meerbeeck J, Musango L, Brusselle G, Joos G, Seminega B, et al. Prevalence of atopy, asthma and COPD in an urban and a rural area of an African country. Respir Med 2011;105:1596-605.

29. Ellison-Loschmann L, King R, Pearce N. Regional variations in asthma hospitalisations among Maori and non-Maori. N Z Med J 2004;117:U745

30. Columbo M, Panettieri RA Jr, Rohr AS. Asthma in the elderly: a study of the role of vitamin D. Allergy Asthma Clin Immunol 2014;10:48.

31. Nageswari AD, Rajanandh MG, Priyanka RK, Rajasekhar P. Effect of vitamin D3 on mild to moderate persistent asthmatic patients: a randomised controlled pilot study. Perspect Clin Res 2014;5:167-71.

32. Hollis BW. Circulating 25-hydroxyvitamin D levels indicative of vitamin D sufficiency: implications for establishing a new effective dietary intake recommendation for vitamin D. J Nutr 2005;135:317-22.

33. Menon B, Nima G, Dogra V, Mittal A, Kaur C, Mittal U. Evaluation of vitamin $\mathrm{D}$ in bronchial asthma and the effect of vitamin D supplementation on asthma severity and control: a randomised control trial. Eur Respir J 2014;44:4049.

34. Miyake Y, Sasaki S, Tanaka K, Hirota Y. Dairy food, calcium and vitamin $\mathrm{D}$ intake in pregnancy, and wheeze and eczema in infants. Eur Respir J 2010;35:1228-34.

35. Aldubi HM, Alissa EM, Kamfar HZ, Gaber O, Marzouki ZM Bronchial asthma and hypovitaminosis D in Saudi children. Asian Pac Allergy 2015;5:103-13.

36. Gupta A, Bush A, Richards D, Hawrylowicz C, Saglani S. Serum vitamin D levels and severe therapy-resistant asthma in children. Arch Dis Child 2011;96:A13.

37. Korn S, Hübner M, Jung M, Blettner M, Buhl R. Severe and uncontrolled adult asthma is associated with vitamin D insufficiency and deficiency. Respir Res 2013;14:25.

38. Brightling C, Berry M, Amrani Y. Targeting TNF-alpha: a novel therapeutic approach for asthma. J Allergy Clin Immunol 2008;121:5-10.

39. Peterson CA, Heffernan ME. Serum tumor necrosis factoralpha concentrations are negatively correlated with serum $25(\mathrm{OH}) \mathrm{D}$ concentrations in healthy women. J Inflamm (Lond) 2008;5:10.

40. Holick MF. Vitamin D deficiency. N Engl J Med 2007;357:266-81.

41. Hewison M. Antibacterial effects of vitamin D. Nat Rev Endocrinol 2011;7:337-45.

42. Lan N, Luo G, Yang X, Cheng Y, Zhang Y, Wang X, et al. 25Hydroxy vitamin D3-deficiency enhances oxidative stress and corticosteroid resistance in severe asthma exacerbation. PLoS One 2014;9:e111599.

43. Sutherland ER, Goleva E, Jackson LP, Stevens AD, Leung DY. Vitamin D levels, lung function, and steroid response in adult asthma. Am J Respir Crit Care Med 2010;181:699-704.

\section{How to cite this article}

- $\quad$ Rasha Saadi Abbas, Manal Khalid Abdulridha, Mostafa Abdalfatah Shafek. Clinical evaluation of the potential anti-inflammatory effect of vitamin D3 adjuvant therapy for chronic asthma in Iraqi patients. Int J Pharm Pharm Sci 2017;9(1):139-144. 